Session number 3664

\title{
Travelogue from the Materials World: A first week laboratory activity
}

\author{
Katherine C. Chen, Blair London, Linda Vanasupa, Timothy T. Orling, and \\ Lisa Christensen \\ Materials Engineering Department, California Polytechnic State University, \\ San Luis Obispo, CA
}

\begin{abstract}
$\underline{\text { Abstract }}$
A fun, yet educational, laboratory activity was developed for the first week of an introductory Materials Engineering laboratory in order to set the stage for the rest of the quarter. The class is broken up into 8 teams, and each team performs a different experiment during each lab period. The teams then rotate lab experiments each week in a round robin manner, and thus teamwork is an important component of the class. In order to quickly promote team bonding the very first week, each team goes on a materials scavenger hunt together. A variety of materials-related items are to be found around the campus, and various questions must be answered for each item. In addition, each scavenger hunt item is photographed with a Polaroid I-zone camera that produces sticker pictures. While the students work together, they are also being exposed to several materials engineering concepts (many of which will be covered in the lab). The students realize the impact of materials in their daily lives and in the world around them through this activity. The relatively inexpensive lab activity can be easily modified to suit the needs of different instructors. The assignment, procedures, and assessment of the lab activity will be discussed.
\end{abstract}

\section{Background}

An introduction to Materials Engineering Laboratory (MATE 215) at the California Polytechnic State University ("Cal Poly"), San Luis Obispo, is designed to accompany the lecture portion of Materials Engineering (MATE 210). Roughly 12 sections of the lab are offered each quarter, and thus about a total of 750 students take the course every year. Many students from the College of Engineering are required to take the lab as a support course.

The lab embodies the Cal Poly philosophy to "learn by doing," and offers eight separate, 3-hour lab experiments on different topics in materials engineering (e.g., crystal structures, heat treating of steels, tensile testing of polymers). The course runs for 10 weeks, and the class is broken up into teams of three students. Each team does a different lab each week, and then each subsequent week, the labs rotate around until completion of all 8 labs. The teams of students are 
determined (usually by random) during the first week, and are kept throughout the quarter. At the first meeting of the class, lab orientation and safety, as well as team and lab assignments, are typically done. In order to make better use of the first lab meeting and to assist team building, a new and relatively simple activity was developed in Fall 2003 as an introduction to the "Materials World."

\section{$\underline{\text { Objectives }}$}

An important component of the course is for students to work in a team setting and to realize the benefits of teams. The instructors had noticed that it typically took a few weeks for the students to actually start functioning well together as a team, and that sometimes students would go through the entire quarter without even knowing their teammates' names. In addition, feedback from our industrial advisory board and ABET objectives ${ }^{1}$ stress the ability for students to work on a diverse team. In order to have the students be comfortable and able to work with their teammates on their very first lab experiment (during the second week), we decided that the students should participate in some type of fun, yet educationally worthwhile, activity together.

Meanwhile during the first week of lectures, most instructors are introducing the material classes and the goals of materials engineering (e.g., materials selection, the processing-structureproperty-performance tetrahedron $)^{2}$. While most students quickly comprehend the metals, ceramics, and polymers classification schemes, explanations and applications of the materials classes are not as easily forthcoming. The lab activity we developed embraces an "active learning" style ${ }^{3}$, and has the students walk around the campus looking for real life examples of each materials class. The students thereby discover the Materials World we all live in and realize the importance of materials in everyday objects.

With each example of an engineered object, the most important or key property of the object must also be identified. For example, a plastic water bottle is an example of an engineered polymer product, and the key property for the liquid container could be low weight, flexibility, or transparency. Materials selection is thus incorporated into the activity. The students must determine what the key requirement for the application is, and connect the type of material that satisfies that requirement.

Table 1. Objectives of the First Week Laboratory Activity

- bond with team members

- give real world examples of each of the basic Materials Classes (i.e., metals, ceramics, polymers, composites)

- describe characteristics of each of the basic Materials Classes

- identify the key property of an engineered object

- discuss the role of materials engineering in everyday objects 
The first week activity also must be completed within 60-90 minutes, and not require extensive knowledge of materials engineering concepts. Setting the correct mind frame to the course was accomplished by introducing some of the concepts of materials that would be encountered later in the lab (and lectures). This activity serves as a positive prologue to materials engineering, and the objectives are listed in Table 1.

\section{Laboratory Activity}

Similar to visiting foreign countries, the venture (or introduction) into the Materials World necessitates exploration and documentation with a travelogue that includes pictures. The itinerary for this lab activity is provided in the form of a scavenger hunt list. Ten objects are to be found and photographed, and a few questions must be answered for each item. The objects are somewhat open-ended such that each team can have different objects for each required item. For instance, the engineering alloy item garnered objects such as bike frames, cars, and sign posts. In addition, the rules stipulate that 10 different objects must be found, and that the same object can not be used for multiple scavenger hunt items. Each team is given an inexpensive I-zone Polaroid camera that produces small (1" x 1.5"), instant photographs with an adhesive backing.

The scavenger hunt list is organized into subtopics of Structural Materials, Electronic Materials, and Cool Materials Stuff. The scavenger hunt items are listed in Table 2. The list also includes a short description of the items and gives questions to be answered. A worksheet is also provided to post each Polaroid photograph and to answer all the questions. Part of a completed worksheet is provided in Figure 1. Most of the entries on the worksheet follow the same format: photograph, identification of photograph, location of object, key material property of the application, and answer to the specific question (on the scavenger hunt list). The graded worksheets from all the sections are complied together in a large binder for each quarter.

Table 2. Materials Scavenger Hunt Items and Questions

\section{Team}

1. Find someone to take a photograph of your team. Write down your names in the space provided on the Worksheet. Be sure we can tell which name corresponds to which person. Question: What is each person's major and year at Cal Poly?

Structural Materials - used to carry loads

2. Locate an engineering alloy that is currently being used as a structural material. Alloys are mixtures of two or more metallic elements. Question: What is the name of the alloy and the major elements in it, for your application?

3. Find an engineering polymer (plastic) currently in use as a structural material. Polymers are nonmetallic (usually based on carbon) composed of small molecular repeat units (mers). Question: Why is a polymer used for this particular application vs. other material classes?

4. Seek out an engineering ceramic used as a structural material. Ceramics are nonmetallic 
materials that usually have the characteristics of being hard, strong, brittle, and extremely heat-resistant (high melting points). Question: How did you determine that the material you photographed was a ceramic rather than another material class ( 3 criteria)?

5. Locate an engineering composite being used as a structural material. Composites are combinations of two or more materials that have superior properties as a mixture rather than as individual phases. Question: Which engineering discipline might use composites the most? Why?

Electronic Materials - used in electronic, optical, or magnetic applications

6. Find a semiconductor material in an application as an electronic material. Note: you do not need to disassemble some electronic device to get at the semiconductor... it's fine to take a photograph of the device itself. Semiconductors have electrical conductivities between that of metals and insulators, achieved by having a certain sized band gap $(<2 \mathrm{eV})$ between the valence and conduction energy bands. Question: Could your application be achieved with an alternate material, and how would that material affect the performance in the application?

\section{Cool Materials Stuff}

7. Locate an example of the microstructure of an engineering alloy. Microstructure deals with how a certain material appears on the millimeter or sub-millimeter scale. It can include such features as grains or various phases. BIG HINTS: The galvanized coating on: the street signposts ... some Mustang Daily receptacle lids...the railings by the library...the poles for parking meters show the microstructure of the metallic surface grains Question: Why put the galvanized coating on the signpost? ANOTHER HINT: Think of what material is likely underneath the galvanized coating.

8. Seek out an example of corrosion of an engineering alloy. Corrosion is the loss of metal as a result an electrochemical reaction (e.g., rust on steel). Question: Is the corrosion you found deleterious (damaging), decorative, or protective to the material? Explain a bit.

9. Find an example of material fracture. Fracture involves the separation of an engineering component into two or more pieces. Sometimes you can catch a fracture in process, for example when an engineering component is cracking... Question: Why did the material fail in the application you found?

10. Locate an example of a product that could be made from more than one type of material class. Material substitution happens all the time in engineering. For example, years ago most children's toys were made of metal, now they're made of plastic. Question: What are the material classes and the advantages of each class for the application you found?

After announcements for the lab course are made and teams are formed, a brief explanation of the different classes of materials is presented. Equipment for the scavenger hunt are passed out, and are listed in Table 3. Directions and rationale for the scavenger hunt are given, and then the teams are let loose and the hunt begins! The first item is a photograph of the team (with the requisite caption of all the names), and serves as an instant ice breaker.

All items on the scavenger hunt list can easily be found within a block of the lab room. However, the students are encouraged to wander around the campus to find good examples. The 
teams can also ask the instructor questions during the activity for clarification or explanations. The Polaroid pictures develop within a few minutes, and the edges of the film are cut with scissors. A thin plastic covering on the back of the photo is removed to reveal an adhesive backing to stick to the worksheet. The team of students must then collectively discuss and answer the given question for each item. Due to the different tasks involved (such as taking the picture, cutting and affixing the picture, writing out the responses on the worksheet), teamwork is essential. No one person can do all the work very efficiently. Through this simple activity, the teams become "cooperative learning groups," 4 and continue to strive to do well together during the quarter.

An unfortunate and unintended result of the hunt was that students carelessly littered the photowaste across the Cal Poly campus. Even though students were given a plastic bag and instructed to collect the waste, instructors continue to find bits and pieces of the I-zone film strewn across the campus. In Winter 2004, a new system was implemented to avoid littering: Students were

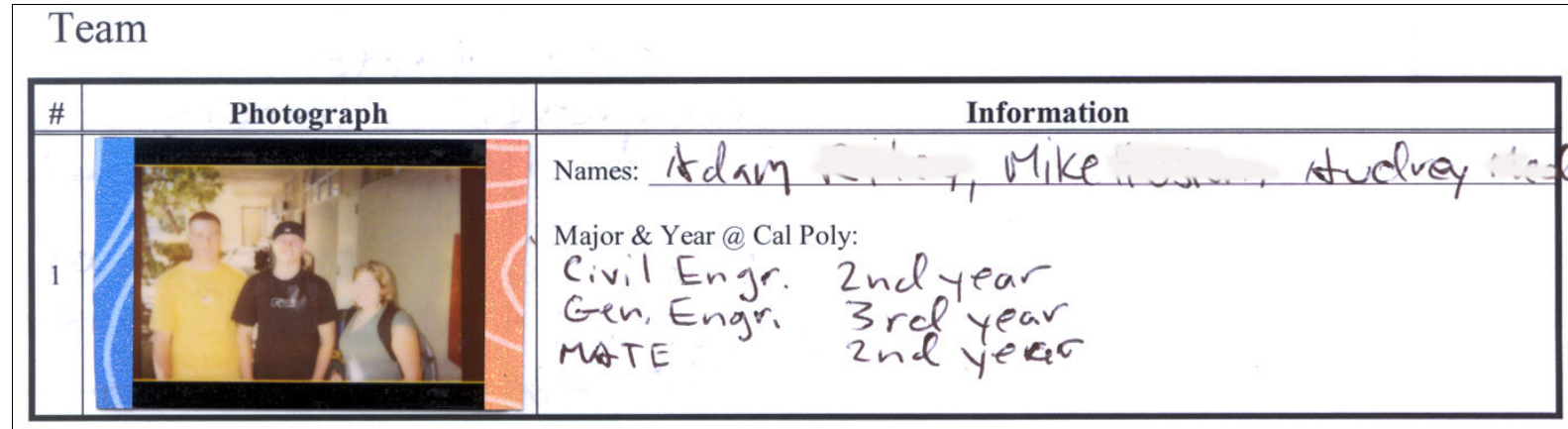

\section{Structural Materials}

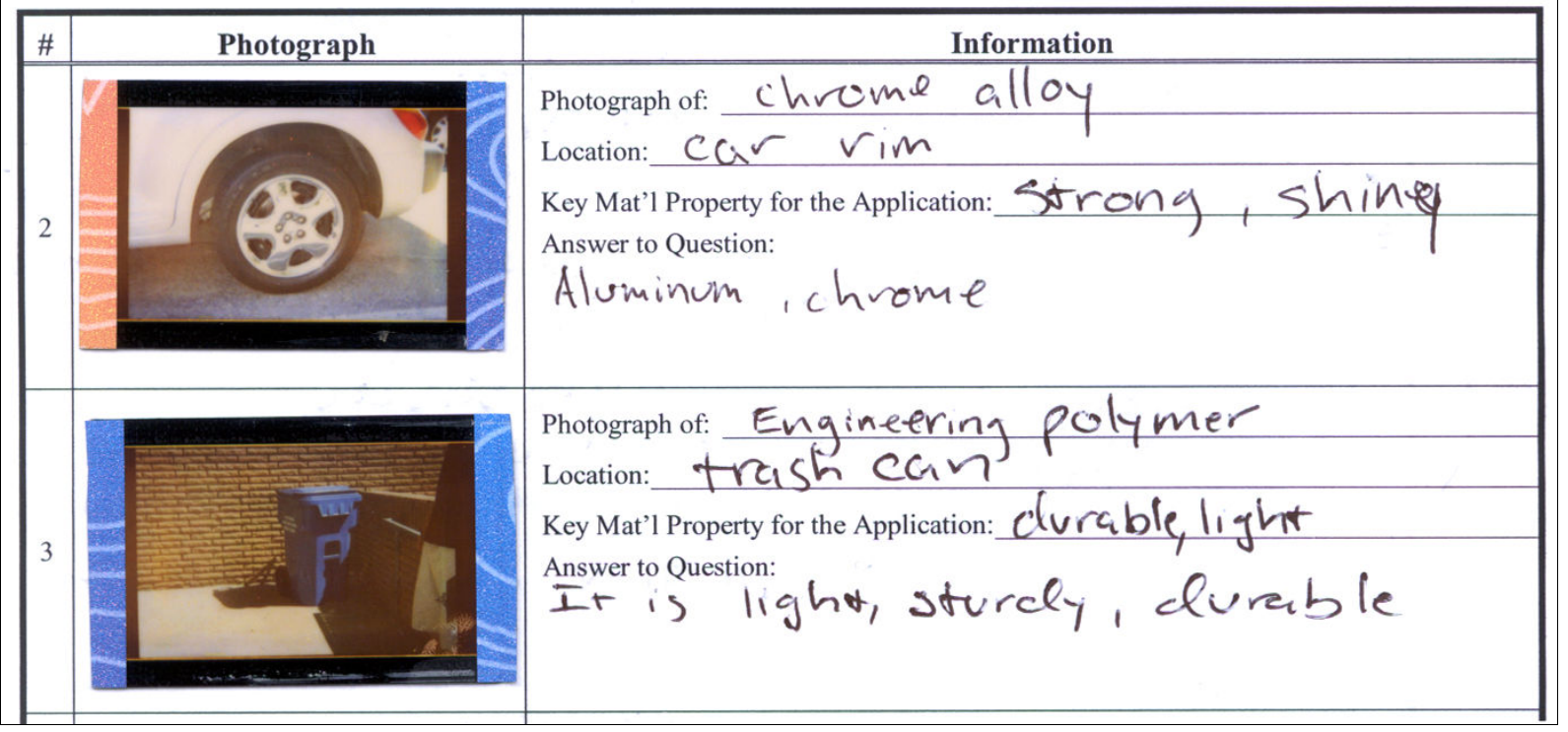

Figure 1. Partial worksheet of items \#1-3 of the Materials Scavenger Hunt. 
told they must account for every scrap of waste upon returning or they would receive an "ecopenalty" (i.e., their score of the lab would be lowered). When the students returned, they were instructed to organize their waste to demonstrate they had returned with it. Surprisingly, each of the groups was able to account for every scrap of waste (cut pull tabs and clear plastic adhesive backing for every photo taken, empty film canister and aluminum packaging).

While the activity does require funds for the film, it is still relatively cheap compared to the other experiments in the course. The Polaroid I-zone cameras ${ }^{5}$ are a one-time, up front cost, and cost about $\$ 10$ a piece. Each film package with 12 exposures costs roughly $\$ 2.50$ in a bulk rate. The cameras have served our department well also as a means to quickly learn names with the faces of students.

\begin{tabular}{l} 
Table 3. List of equipment for the Materials Scavenger Hunt \\
\hline scavenger hunt list \\
clip board \\
Polaroid I-zone camera \\
Polaroid sticker film with adhesive backing (12 exposure) \\
scissors \\
plastic bag for photograph ends and backing
\end{tabular}

\section{$\underline{\text { Assessment }}$}

The scavenger hunt activity was implemented this school year, but based on the reception thus far, the activity will continue in the future. The instructors found the activity to require very little preparation and it appeared that most of the students genuinely enjoyed the experience. A survey on the activity was given at the end of the quarter (roughly 10 weeks afterwards) and the students' comments on what they learned from the activity are given below in italics, along with some of the analysis.

\section{Team Building}

The activity proved to engage the students, and the students within the teams quickly learned each others names, attitudes, and learning styles. Some of the instructors commented that they felt that the students worked together better the following week at their first actual laboratory experiment. Some of the student comments follow:

"The scavenger hunt was an awesome icebreaker with my group. It really got us started on the right foot and we transferred that positive energy to our lab work." 
"The most I learned from the activity was how my teammates and I could get along. We were able to talk and feel as if we could hang out without having the pressure of just being "lab" partners."

"It made me realize that materials engineering is used everywhere across campus. I also got to know my teammates because we had time to talk and wander around campus. It was a laid back lab so we didn't have to worry..."

\section{Introduction to Materials}

In addition, the activity was designed to introduce some materials engineering terms within a recognizable context. For example, "microstructure" was a scavenger hunt item, and was explained on the list (Table 2). The students were given the hint to seek out galvanized coating on steel, commonly found on street signposts or steel railings. Microstructures appear in several of the later labs in the course, and the scavenger hunt activity provided initial exposure to the term. Furthermore, polymers, corrosion and fracture are scavenger hunt items and are concepts that come up later in the course.

"Well, for starters it's a good activity for the beginning of the class, when the students are just being introduced to MatE, and don't know what to expect. Doing it helps put focus to what's going on and made later in the course easier to have real world connection too. Secondly it was a fun activity to start the group with, and helped us get closer together, and work more comfortably and efficiently in the labs."

"It was nice to look at materials from a different perceptive. Things you regularly pass by, but give no consideration. I think it helped me get ready for what the lab was all about. It gave me a nice intro to the overall course."

\section{Active Learning}

From a pedagogical standpoint, the activity was often successful when the students discussed what objects fit the criteria (i.e., the scavenger hunt item) and what did not. For instance, although a brick was clearly a ceramic, what made the brick a ceramic? How was it different from a metal or polymer? Things that at first seemed obvious or taken for granted was questioned and needed to be reconfirmed. Verbalizing their thought processes ${ }^{6}$ and considering other viewpoints resulted in more confident understandings ${ }^{7}$.

"Although we knew most of the answers, such as cement is hard but brittle, I didn't know why, and these type of things were exactly what was addressed and learned in this class. The scavenger hunt was a great way to start the quarter."

"It was good because it got our minds working together and one person that knew something more than the other could help the other out."

"Learned that my team had different opinions about the materials which helped us generate better answers." 


\section{Survey Results}

Out of the 179 responses to the survey, $71 \%$ of the students felt that the materials scavenger hunt was worthwhile and should be continued for future students. $76 \%$ agreed with the statement that the materials scavenger hunt allowed their lab team to be able to work efficiently for the first lab experiment. The point at which the students felt comfortable working with their team is displayed in Figure 2. After the scavenger hunt activity and before the first actual lab, $62 \%$ of the students were already at ease working with their team. An additional $22 \%$ were comfortable during the first lab experiment in the second week of the course.

Improvements for the next time include giving a better explanation of what "properties" are and perhaps giving some examples of how to fill out the worksheet. Prizes may also be given out to students or teams finding the best or most creative objects in the scavenger hunt.

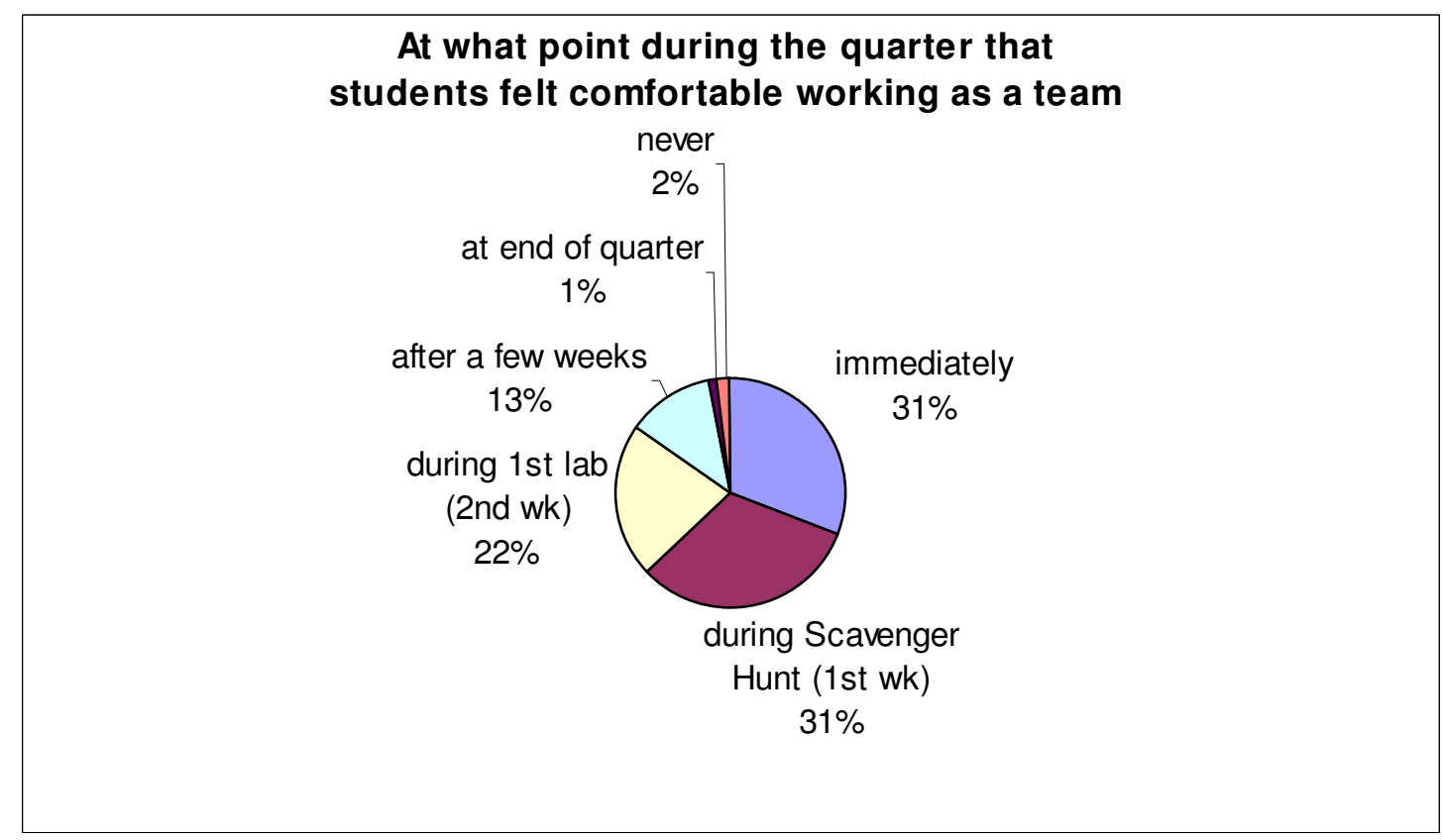

Figure 2. Survey results of when students ( $\mathrm{n}=179$ students) felt comfortable working in their teams. After the scavenger hunt activity during the first week of the lab, $62 \%$ of the students were comfortable working as a team.

\section{Conclusions}

Our new, first week lab activity provides a fun and innovative way to set the stage for the rest of the course. The materials scavenger hunt (with pictures and questions) accomplishes our objectives to get the students working together as teams. The students also gain the ability to differentiate everyday engineered objects into specific materials classes. The activity can be easily modified to meet the needs of individual instructors, and will be continued at Cal Poly. 


\section{Bibliography}

1. Accreditation Board for Engineering and Technology (ABET), Criteria for accreditation engineering programs, Engineering Accreditation Commission of the Accreditation Board for Engineering and Technology, 2000.

2. William D. Callister, Jr. Materials Science and Engineering An Introduction, John Wiley \& Sons, Inc., 2003.

3. www.active-learning-site.com/

4. Karl A. Smith, Teamwork and Project Management, 2nd ed., McGraw Hill, 2000.

5. www.i-zone.com/izone/index.jsp

6. Rodney W. Napier and Matti K. Gershenfeld, Groups: Theory and experience, Houghton Miffin, 1973.

7. mazur.deas.harvard.edu/education/educationmenu.php

\section{Biographical Information}

KATHERINE C. CHEN is an Associate Professor in the Materials Engineering Department at Cal Poly State University, San Luis Obispo, CA. She received her bachelor degrees (in Chemistry and Materials Science \& Engineering) from Michigan State University, and Ph.D. from the Massachusetts Institute of Technology. At Cal Poly, she teaches undergraduate students Structures of Materials, Kinetics of Materials, and various other courses.

BLAIR LONDON is a Professor in the Materials Engineering Department at Cal Poly State University, San Luis Obispo, CA. He received his bachelor degree in Materials Engineering at Drexel University. His M.S. and Ph.D. degrees are from Stanford University. He teaches a wide variety of materials engineering courses.

LINDA VANASUPA is a Professor and Chair of the Materials Engineering Department at Cal Poly State University, San Luis Obispo, CA. She received her bachelor degree (Metallurgical Engineering) from Michigan Technological University, and M.S. and Ph.D. degrees from the Stanford University.

TIMOTHY T. ORLING is a Lecturer in the Materials Engineering Department at Cal Poly State University, San Luis Obispo, CA. He received his B.S. degree from Cal Poly, his M.S. degree from Rensselaer Polytechnic Institute and is pursuing his Ph.D. from the University of California, Davis. He teaches undergraduate students in Ceramics, Thermodynamics of Materials, and other courses.

LISA M. CHRISTENSEN is an engineering graduate student at Cal Poly State University, San Luis Obispo, CA. She received her bachelor's degree in Materials Engineering from Cal Poly in 2002. While completing her master's, she is teaching a survey materials engineering laboratory to undergraduates and training students to use the Scanning Electron Microscope. 